\title{
O PROCESSO ELETRÔNICO COMO EFETIVAÇÃO DO DIREITO FUNDAMENTAL DE ACESSO À JUSTIÇA
}

\author{
Ana Carolina Fonseca Martinez Perez* \\ Roberto Brocanelli Corona**
}

\begin{abstract}
SUMÁRIO: Resumo Abstract 1. Introdução 2. O acesso à justiça e o processo 2.1. A crise do processo 3. O uso da tecnologia no processo como meio de efetivação do direito fundamental de acesso à justiça 4.O processo eletrônico no Brasil e as metas do Conselho Nacional de Justiçasobre o tema 5. A lei no 11.419/2006 6. O processo eletrônico sob o prisma dos Direitos Humanos 7. Conclusão 8. Bibliografia.
\end{abstract}

- RESUMO: O propósito deste artigo é apontar o processo eletrônico como instrumento na realização do direito fundamental de acesso à justiça. Não basta a garantia formal. O Estado democrático de direito há de buscar meios de superação dos muitos e variados entraves em seu sistema judicial, para concretizar o ideal de |Justiça acessível para todos. O uso dos recursos eletrônico, de modo a afastar as mazelas do sistema onde "o processo é lento e os procedimentos demasiadamente complexos sem falarmos do, no mínimo, exagerado sistema recursal e impugnativo nacional." (Gajardoni, Fernando da Fonseca. Técnicas de aceleração do processo/Fernando da Fonseca Gajardoni.- São Paulo: Lemos \& Cruz, 2003, pp.15/16).

- Palavras-chave: Processo Eletrônico. Acesso à Justiça. Garantias fundamentais.

- ABSTRACT: The purpose of this article is to show the electronic process as an instrument to realize the fundamental right: the access to the justice. In order to the formal guarantee is not enough. The democratic country ought to prosecute the ways to superate the various and lots of shackles of its judicial system, in order to render concrete the justice for all as a goal. The use of electronics resources, as a form to minimize the fails of the system where "the process is slow and the procedures are extremely complex and, at least, extremely burocratic of Brazil's system of appeals" (Gajardoni, Fernando da Fonseca. Técnicas de aceleração do processo/Fernando da Fonseca Gajardoni.- São Paulo: Lemos \& Cruz, 2003. pp.15/16).

- Keywords: Eletronic Process. Access to Courts. Constitutional rights.

\section{INTRODUÇÃO}

O presente artigo busca apresentar o processo eletrônico como um instrumento de efetivação do direito fundamental de acesso à justiça. Direito este que muito carece de efetividade, pois estar previsto no rol dos direitos fundamentais, por si só, não basta e por isso, o Conselho Nacional de Justiça (CNJ) tem como uma de suas metas tornar todos os processos virtuais em um futuro próximo.

No artigo $5^{\circ}$, inciso XXXV da Constituição Federal de 1988 prevê:

"A lei não excluirá da apreciação do Poder Judiciário, lesão ou ameaça a direito", ou seja, o direito de acesso à justiça ou acesso à ordem jurídica justa ou acesso ao Judiciário, como assinala

\footnotetext{
"Mestranda na Universidade Estadual Paulista "Júlio de Mesquita Filho"- UNESP; anacarolinaperez@gmail.com.

${ }^{* *}$ Roberto Brocanelli Corona - mestre e doutor em Direito pela PUC-SP, professor da graduação e pós-graduação em Direito da UNESP/Franca-SP.
} 


\begin{abstract}
notável parte da doutrina, tem como escopo a busca efetiva do direito tutelado. Neste sentido, definir a expressão "acesso à justiça" é de difícil tarefa como apontam Mauro Cappelletti e Bryan Garth de que "serve para determinar duas finalidades básicas do sistema jurídico - o sistema pelo qual as pessoas podem reivindicar seus direitos e/ou resolver seus litígios sob os auspícios do Estado. Primeiro, o sistema deve igualmente acessível a todos; segundo, ele deve produzir resultados que sejam individual e socialmente justos". ${ }^{1}$
\end{abstract}

Assim, o acesso à justiça desenvolveu-se com a evolução e mudança pela qual a sociedade passou, de modo que tudo hoje no mundo é realizado da forma mais rápida aos anseios populares. Neste mesmo diapasão deve caminhar o direito, em especial o direito processual, o qual sofre um impacto substancial por estar ainda em descompasso com a realidade atual.

\title{
2. O ACESSO À JUSTIÇA E O PROCESSO
}

O acesso à justiça não é somente ingressar com o processo em si, mas haver condições de nele se concretizar seus direitos e isso deve se dar de forma célere e efetiva. Neste sentido, prevê o artigo 125, inciso II, do Código de Processo Civil na seção I - dos poderes, dos deveres e da responsabilidade do juiz: "O juiz dirigirá o processo conforme as disposições deste Código, competindo-lhe: (...) II- velar pela rápida solução do litígio;".

Todavia, para o juiz dar respaldo e poder cumprir este dever, é preciso que os meios lhe fornecidos (e não só para ele, mas para todos os operadores do direito) sejam capazes de dar vida a isso, e dentre eles o processo, que é o instrumento para se prestar a tutela jurisdicional e algo necessário para se obter uma satisfação em determinado fato que pelas vias extrajudiciais não foi possível alcançar.

Afirma Cândido Rangel Dinamarco que:

\begin{abstract}
“Acesso à justiça não equivale a mero ingresso em juízo. A própria garantia constitucional da ação seria algo inoperante e muito pobre se se resumisse a assegurar que as pretensões das pessoas cheguem ao processo, sem garantir-lhes também um tratamento adequado. É preciso que as pretensões apresentadas aos juízes cheguem efetivamente ao julgamento de fundo, sem a exacerbação de fatores capazes de truncar o prosseguimento do processo, mas também o próprio sistema processual seria estéril e inoperante enquanto se resolvesse numa técnica de atendimento ao direito de ação, sem preocupações com os resultados exteriores. Na preparação do exame substancial da pretensão, é indispensável que as partes sejam trata-
\end{abstract}

${ }^{1}$ CAPPELLETTI, Mauro. Acesso à justiça. Tradução de Ellen Gracie Northfleet. Porto Alegre, Fabris, 1988, p.8 
das com igualdade e admitidas a participar, não se omitindo da participação também o próprio juiz, de quem é a responsabilidade principal pela condução do processo e correto julgamento da causa. Só tem acesso à ordem jurídica quem recebe justiça. E receber justiça significa ser admitido em juízo, poder participar, contar com a participação adequada do juiz e, ao fim, receber um provimento jurisdicional consentâneo com os valores da sociedade. Tais são os contornos do processo justo, ou processo équo, que é composto pela efetividade de um mínimo de garantias de meios e de resultados." 2

Assim, o processo se torna alvo de novas tendências no direito processual, pois é o meio pelo qual se efetivará o direito fundamental em tela e ao mesmo tempo é crítica de muitos, pois não consegue cumprir aquilo que lhe é inerente, ou seja, não alcança a celeridade e acaba por imperar, portanto, a morosidade e ineficácia judicial do processo, restando claro a crise no judiciário e no processo.

Isso não é novidade no mundo jurídico e nem fora dele. Neste sentido, Fernando da Fonseca Gajardoni leciona:

“Todos sabemos que o processo é lento e os procedimentos são demasiadamente complexos, sem falarmos do, no mínimo, exagerado sistema recursal e impugnativo nacional. Somemos a isso o excesso de demandas- fruto da conscientização dos cidadãos da necessidade de defenderem seus direitos que alhures eram relegados a um segundo plano-, e o pequeno número de magistrados em atividades- reflexo da precária qualidade de ensino das faculdades de direito nacionais, dos baixos vencimentos oferecidos aos aspirantes ao cargo, do movimento político de desestabilização da classe e da grave crise orçamentária pela qual passa o Poder Público-, e temos o quadro completo do que convencionalmente tem-se denominado crise do judiciário.

Com efeito, os males da corrosão e frustração que o decurso do tempo pode trazer à vida dos direitos constituem ameaça à efetividade da promessa de tutela jurisdicional, ameaça tão grande e tão sentida que, em tempos atuais, se vem afirmando que a garantia do devido processo legal "só se considera efetiva quando prestada de forma tempestiva." ${ }^{3}$

Como o presente artigo cuida especificamente do processo, tecer-se-á apenas considerações sobre o referido tema e a crise em que se encontra, o que torna mais difícil de efetivar o devido direito de acesso à justiça.

\subsection{A CRISE DO PROCESSO}

De acordo com o dicionário de Filosofia e Ciências Culturais crise

\footnotetext{
2. DINAMARCO, Cândido Rangel. Instituições de direito processual civil. São Paulo: Malheiros, 2001. p. 115

3. GAJARDONI, Fernando da Fonseca. Técnicas de aceleração do processo/Fernando da Fonseca Gajardoni. São Paulo: Lemos \& Cruz, 2003. pp.15/16
} 
vem da palavra grega krisis:

“(...) que, etimológicamente, significa separação, abismo, e também, juízo, decisão, etc. Há, em todo o existir, um separar-se, uma crise, quer pela forma, quer pela separação física das coisas. Mas estas não se separam, porém, absolutamente, porque, do contrário, haveria rupturas no ser, o que é absurdo ante uma concepção que não aceita qualquer dualismo nem pluralismo principal. E se a verdade do mundo fosse, a crise se instalaria ainda em maior escala, porque haveria seres absolutamente separados, e infinitamente distantes uns dos outros.

Há, de qualquer forma, de modo absoluto ou não, um separarse entre as coisas. $\mathrm{E}$ é a crise que leva o homem à crítica, ao trabalho analítico, ao exame das partes de um todo, para apreender mais concretamente o todo.

(...)

Deste modo, em todos os campos do conhecimento, e em todos os setores da vida humana, encontramos sempre instalada a crise.(...)" 4

No Dicionário da Língua Portuguesa da Larousse Cultural, da editora moderna, a palavra crise tem também o significado de tensão, conflito.

Já processo vem do latim procedere que significa seguir adiante e é o meio pelo qual a jurisdição se concretiza, sendo, portanto, o instrumento de realização da justiça. Todavia, a atual sociedade vive em constante mudança e está envolvida por uma crise processual, uma vez que o processo não consegue efetivar os anseios da forma que hoje é buscado e assim sendo, não consegue abarcar as novas situações.

Nesse sentido afirma Fernando da Fonseca Gajardoni:

“(...) Nosso processo, concebido como instrumento formal e único de solução de controvérsias individuais, por um órgão jurisdicional exclusivamente estatal, ainda não consegue responder efetivamente aos reclames do direito coletivo e corporativo, nem tampouco solucionar adequadamente os pequenos conflitos.

Além disso, mesmo diante de conflitos, direitos e garantias já conhecidos, há muito contemplados no direito material, o fato é que o processo tradicional não tem sido capaz de solucionar tempestivamente os impasses e assegurar eficazmente as situações jurídicas de vantagem. A tutela jurisdicional invocada até que é oferecida, mas, quando obtida, por tardia, já não tem o condão de recompor as soluções sociais, como de direito". ${ }^{5}$

Portanto, diante de todo o quadro acima exposto, a conclusão inarredável a

\footnotetext{
4. SANTOS, Mário Ferreira dos. Dicionário de filosofia e ciências culturais. $1^{\circ}$ vol.ed. 2. Matese: São Paulo. 1964. pp.389/390

5. GAJARDONI, Fernando da Fonseca. Técnicas de aceleração do processo/Fernando da Fonseca Gajardoni.- São Paulo: Lemos \& Cruz, 2003. p. 32
} 
que se chega é que em nosso sistema judicial não se cumpre o direito constitucionalmente tutelado de acesso á justiça diante da sua precária funcionalidade e ineficiência, já que uma das grandes razões da morosidade e descrédito do Poder Judiciário é a demora na prestação jurisdicional.

\title{
3. O USO DA TECNOLOGIA NO PROCESSO COMO MEIO DE EFETIVAÇÂO DO DIREITO FUNDAMENTAL DE ACESSO À JUSTIÇA
}

Tratando-se, então, a prestação jurisdicional de uma prestação de serviço advinda de uma atividade estatal, e sob esse aspecto, se faz necessário demonstrar a finalidade de otimização dos recursos "do aparato judicial que serve de suporte à realização da jurisdição". (BENUCCI, Renato Luís. A tecnologia aplicada ao processo judicial/Renato Luís Benucci.- Campinas, São Paulo: Millennium Editora, 2006, p.58)

Para atacar esse problema da morosidade e ineficácia do processo como meio de efetivar o direito de acesso à justiça e os direitos em geral, pode utilizar-se da tecnologia e de tudo que ela pode oferecer para amparar o aparato judicial. Nesse contexto, ensina Renato Luís Benucci:

\begin{abstract}
"Não se trata, assim, de um mero investimento tecnológico externo ao processo, mas sim da utilização tecnológica determinante de novos conceitos procedimentais, que vão desde a comunicação de atos processuais, passando pela certificação automática desses atos, até a eliminação total dos papéis. Enfim, modificações que, do ponto de vista processual, não são apenas exógenas, mas também endógenas.

Neste sentido, a aplicação da tecnologia da informação ao processo judicial pode ser entendida como uma amálgama entre os mecanismos judiciais e extraprocessuais de aceleração processual. É, por um aspecto, um mecanismo extraprocessual de aceleração processual porque se baseia na utilização de softwares, equipamentos e máquinas externos ao processo. Entretanto, por outro prisma, também se caracteriza como um mecanismo judicial de aceleração do processo por implicar mudanças no iter processual e no modo de realização dos atos processuais." 6
\end{abstract}

Através do uso da tecnologia no processo poderá ser aferir o real tempo da tramitação processual e mesmo havendo alguns que afirmem ser de alto custo essa modalidade, ainda assim, não se compara com a onerosidade da máquina judiciária que é ineficiente e obsoleta. Não se propõe a utilização da tecnologia no meio processual para reparar todos os males que a morosidade processual traz, sendo necessário para isso os recursos necessários e acompanhamento de capacitação e

\footnotetext{
6. BENUCCI, Renato Luís. A tecnologia aplicada ao processo judicial/Renato Luís Benucci.- Campinas, São Paulo: Millennium Editora, 2006, p. 59

7. Idem pp.60/61
} 
racionalização desses recursos. ${ }^{7}$

Assim, a implantação do processo eletrônico em muito colaborará para a efetivação dos direitos e maior celeridade e economia processual, tornando esse mecanismo uma das formas de possibilitar a concretização do acesso à justiça de maneira efetiva. Tendo em vista esta ponderação, importante é entender como se deu o início dessa busca pelo judiciário brasileiro.

\section{O PROCESSO ELETRÔNICO NO BRASIL E AS METAS DO CONSELHO NACIONAL DE JUSTIÇA SOBRE O TEMA}

No Brasil, o processo eletrônico foi tratado inicialmente pela Lei $n^{\circ} 9.800$ de 26 de maio de 1999, a qual permitia o uso do sistema de transmissão de dados para a prática dos atos processuais e desde esse dia as petições poderiam ser passadas por meio de máquinas que permitiam isso, como por exemplo, o fac-símile. Todavia, só era considerado válido o ato se posteriormente fosse apresentado o original do qual se efetivou a transmissão e assim, pode-se dizer que esta lei não trouxe muita evolução para o processo mas já foi o ponto inicial capaz de trazer à baila idéias mais progressistas. ${ }^{8}$

Com o advento da Lei $\mathrm{n}^{0} 11.419$ de 19 de dezembro de 2006 foi possível vislumbrar idéias inovadoras em relação ao processo uma vez ser este viabilizado por meio eletrônico sendo definido pelo próprio estatuto legal como "qualquer forma de armazenamento ou tráfego de documentos e arquivos digitais" (artigo $1^{\circ}$, parágrafo $2^{\circ}$, inciso I).

Assim, muitas características positivas serão proporcionadas através do processo informatizado, tendo como uma delas a celeridade processual, algo que na sociedade em que se vive é muito prezado. Além disso, efetivando alguns princípios constitucionais que constam apenas em um rol no qual o cidadão não consegue de fato ter garantido, como no caso de um processo célere, implica diretamente no direito de acesso à justiça, ou seja, o acesso à justiça se torna mais "palpável" para todos quando se tem de forma definitiva, efetiva e segura, assegurado o direito que se pleiteia.

Isso não quer dizer, como já mencionado anteriormente, que o processo eletrônico irá sanar todas a mazelas e entraves existentes no processo hoje mas pode viabilizar uma amenização no Poder Judiciário, criando uma nova visão desse poder e afastando a descrença que hoje é tida por muitos.

Logo, como uma busca de efetivar o acesso à justiça bem como trazer efetividade aos princípios constitucionais da duração razoável do processo, celeridade, e outros, o Conselho Nacional de Justiça estabeleceu dez metas no ano de 2009, dentre elas as metas 3 (três), 4 (quatro) e 10 (dez), em especial, que estabelecem, respectivamente, informatizar todas as unidades judiciárias e interligá-

\footnotetext{
8. FORTES, Rafael Costa. Informatização do judiciário e o processo eletrônico. http://jus2.uol.com.br/ doutrina/texto.asp?id=14101\&p=2, acessado em 20/10/2010
} 
las ao respectivo tribunal e à rede mundial de computadores (internet), informatizar e automatizar a distribuição de todos os processos e recursos, e implantar o processo eletrônico em parcela de suas unidades judiciárias.

Assim, com o acordo feito entre o Conselho Nacional de Justiça e os cinco tribunais regionais federais para o desenvolvimento do processo eletrônico qualquer tipo de procedimento poderá adotar essa meio para desenvolver o processo tendo em vista as metas acima planejadas.

Como resultado das metas, no relatório final, em nível nacional, a meta três foi realizada em $96,70 \%$ enquanto a meta quatro foi de $96,30 \%$ e a meta dez foi de $43,33 \%$, todos em relação a média nacional. ${ }^{9}$ Interessante notar a queda substancial em relação ao processo eletrônico com os outros percentuais e tendo em vista que o relatório aponta a Justiça Federal haver cumprido integralmente esta meta, em contrapartida o Tribunal Superior Eleitoral não cumpriu nada. E qual foi o "aprendizado institucional dos tribunais" com relação a essas metas?

Referente a meta 3 os tribunais afirmaram que as dificuldade para seu cumprimento foram: dificuldades de acesso em função das dimensões geográficas em algumas regiões; falta de infraestrutura de comunicação, principalmente devido à ausência de prestação de serviços de empresas de telecomunicações em determinadas regiões; custo de implementação de links; ausência de links de qualidade; insuficiência de mão de obra especializada em TI; falta de orçamento suficiente para a execução da meta. Para melhorar esse quadro, foram adotadas as seguintes medidas: foi realizado um convênio para o uso do CENSIPAM (interligação via satélite das comarcas da Amazônia Legal) firmado entre o CNJ e o Poder Executivo Federal; aquisição de aceleradores de WAN (redes de longa distância), para doação aos tribunais situados na Amazônia Legal além da consolidação da Infovia, com interligação eletrônica entre os tribunais e o CNJ, assim como a criação de rede integrada tornar possível a melhoria do serviço judicial e integração do Poder Judiciário.

Com relação a meta 4 foram encontradas as seguintes dificuldades: dificuldade orçamentária para custear o deslocamento dos técnicos, bem como a logística, a falta do de um número mínino de corpo técnico e de infraestrutura de comunicação e de rede além da carência de pessoal especializado na área de TI, havendo como medidas adotadas para melhorar o quadro evitar fraudes na distribuição dos processos, a agilidade na distribuição dos processos e garantir a eqüidade de trabalho entre os magistrados.

Em última análise, a meta 10, de suma importância para o presente artigo, teve como entraves a falta de autonomia/disponibilidade orçamentária para a implantação do programa (aquisição de equipamentos de armazenamento, contratação de links adequados, etc), bem como ausência de uniformização dos sistemas entre os tribunais por segmento judiciário, a falta de pessoal especializado

\footnotetext{
9. http://www.cnj.jus.br/images/hotsites/relatorio_cnj_formato_cartilhav2.pdf acessado em 23/10/2010 
e estrutura adequada na área de Tecnologia da Informação para atender os diversos projetos de TI e as dificuldades na sensibilização dos usuários para utilização dos sistemas do processo eletrônico. Como medidas a serem adotadas e melhorias observadas foram a ampliação substancial na utilização do processo eletrônico assim como maior mobilização dos tribunais para implantação do processo eletrônico e disseminação da cultura desse processo eletrônico além da coordenação do CNJ no desenvolvimento do sistema de processo eletrônico adequado a todos os segmentos do Poder Judiciário, iniciado por acordo firmado entre o CJF e os TRF's seguido de envolvimento dos demais segmentos do Poder Judiciário. ${ }^{10}$

\title{
5. A LEI No 11.419/2006
}

Posto todas essas estatísticas resta, por fim, tecer alguns comentários acerca da Lei $\mathrm{n}^{\circ}$ 11.419/2006 que cuida do processo eletrônico e nessa perspectiva de utilizálo como instrumento possível de garantia de acesso à justiça.

Sobre esse ponto é importante ressaltar a terceira onda da qual Mauro Cappelletti e Bryant Garth ensinam, dentro do Capítulo III- "As Soluções Práticas par os Problemas de Acesso à Justiça", sendo necessário explicar, primeiramente que esta onde se caracteriza como aquela em que "centra sua atenção no conjunto geral de instituições e mecanismos, pessoas e procedimentos utilizados para processar e mesmo prevenir disputas nas sociedades modernas. (...)Seu método não consiste em abandonar as técnicas das duas primeiras ondas de reforma, mas em tratá-las como apenas algumas de uma série de possibilidades para melhorar o acesso" (Cappelletti, Mauro. Acesso à justiça. Tradução de Ellen Gracie Northfleet. Porto Alegre, Fabris, 1988, pp. 67/68)

Mais à frente preleciona o sobredito autor que:

\begin{abstract}
"Inicialmente, como já assinalamos esse enfoque encoraja a exploração de uma ampla variedade de reformas, incluindo alterações nas formas de procedimento, mudanças na estrutura dos tribunais ou a criação de novos tribunais, o uso de pessoas leigas ou para profissionais, tanto como juízes quanto como defensores, modificações no direito substantivo destinadas a evitar litígios ou facilitar sua solução e a utilização de mecanismos privados ou informais de solução dos litígios". ${ }^{11}$
\end{abstract}

Assim, o processo eletrônico veio adaptar o processo ao tipo de litígio que hoje se tem na sociedade. Litígio que necessita ter um Judiciário prestador de serviços céleres e eficazes, de modo que possibilite tirar alguns entraves do Poder Judiciário, caracterizando assim, essa terceira onda na qual se possa vislumbrar um efetivo acesso à justiça.

\footnotetext{
10. http://www.cnj.jus.br/images/hotsites/relatorio_cnj_formato_cartilhav2.pdf - acessado em 23/10/ 2010

11. CAPPELLETTI, Mauro. Acesso à justiça. Tradução de Ellen Gracie Northfleet. Porto Alegre, Fabris, 1988, p.71
} 
Neste diapasão ensina José Carlos de Araújo Almeida Filho:

"Como forma de desafogar o Judiciário e até mesmo eliminar os entraves burocráticos havidos nos cartórios, a população mais carente teria maior acessibilidade a todos os meios para a concretização de seus direitos. Um procedimento eletrônico é rápido e eficaz e as experiências vivenciadas no Brasil demonstram ser possível a inserção desta forma no processo.

Analisando sob este prisma e repudiando o anacronismo dos que ainda resistem à informática no direito, a partir do momento em que temos a inserção de um novo mecanismo, ainda que acessível - ao menos inicialmente - a poucos, teremos um grande espaço aberto para as questões que necessitam de imediata intervenção do Judiciário, como as possessórias, de vizinhança, de família, dentre outras que assoberbam a Defensoria Pública, pela demora no processamento dos feitos sob o pálio da gratuidade de Justiça.

Adotar o processo (ou procedimento) eletrônico, é garantir efetividade e acesso aos mais necessitados, sem que possa parecer uma assistência caridosa.

Finalmente, a fim de nos adequarmos à terceira onda, para as questões envolvendo informática e conflitos provocados na Internet, a necessidade de adoção do procedimento eletrônico." 12

Com a Lei do Processo Eletrônico, busca-se, na medida do possível, acabar com a imagem da morosidade do Judiciário no Brasil e trazer efetividade a todos de acesso à justiça, de modo que os litígios sejam solucionados dentro de uma duração razoável do processo. Neste sentido afirma Mauro Cappelletti e Bryant Garth:

“Em muitos países, as partes que buscam uma solução judicial precisam esperar dois ou três anos, ou mais, por uma decisão exeqüível. Os efeitos dessa delonga (...) aumenta os custos para as partes e pressiona os economicamente fracos a abandonar suas causas, ou a aceitar acordos por valores muito inferiores àqueles a que teriam direito. A Convenção Européia para Proteção dos Direitos Humanos e Liberdades Fundamentais reconhece explicitamente, no artigo $6^{\circ}$, parágrafo $1^{\circ}$, que a Justiça que não cumpre suas funções dentro de "um prazo razoável" é, para muitas pessoas, uma Justiça inacessível." ${ }^{13}$

Neste mesmo sentido afirma Humberto Theodoro Júnior in Comentários à Lei do Processo Eletrônico in Um Contexto Multiforme de Acesso à Prestação Jurisdicional: Art.2 , a Tramitação Processual Eletrônica de Wesley Roberto de Paula:

12. ALMEIDA FILHO, José Carlos de Araújo,1967 - Processo eletrônico e teoria geral do processo eletrônico: a informatização judicial no Brasil/José Carlos de Araújo Almeida Filho. - Rio de Janeiro: Forense, 2010, pp. 20/21

13. Grifo nosso. CAPPELLETTI, Mauro. Acesso à justiça. Tradução de Ellen Gracie Northfleet. Porto Alegre, Fabris, 1988, pp. 20/21 


\begin{abstract}
"É lastimável, mas não se pode deixar de reconhecer o regime caótico em que os órgãos encarregados da prestação jurisdicional no Brasil trabalham tanto no ponto de vista organizacional, como principalmente em torno da busca de solução para sua crônica inaptidão para enfrentar o problema do acúmulo de processo e da intolerável demora na prestação jurisdicional. Não há o mínimo de racionalidade administrativa, já que inexistem órgãos de planejamento e desenvolvimento de serviços forenses, nem mesmo estatística útil se organiza para verificar onde e porque se entrava a marcha dos processos." 14
\end{abstract}

Logo, críticas não faltam a respeito da morosidade judicial quanto à prestação

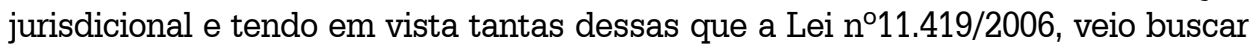
mudar esse quadro do ordenamento jurídico com a implantação do processo eletrônico, tendo em vista a fragilidade e ineficácia do postulado constitucional de acesso à justiça.

Vale ressaltar que o sistema para implantação do processo de informatização judicial foi desenvolvido pelo Tribunal Regional Federal da $5^{\circ}$ Região (TRF5) em conjunto com o Conselho Nacional de Justiça e o pioneiro na informatização do processo judicial foi o Tribunal Regional Federal da $4^{\text {a }}$ Região, no qual determinou que todos os feitos fossem processados perante os Juizados de forma eletrônica e não mais na forma "papel".5(Almeida Filho, José Carlos de Araújo,1967 - Processo eletrônico e teoria geral do processo eletrônico: a informatização judicial no Brasil/ José Carlos de Araújo Almeida Filho. - Rio de Janeiro: Forense, 2010, p.21).

Portanto, diante de todo o exposto neste artigo é possível afirmar que um dos grandes problemas do Judiciário brasileiro está na morosidade na prestação jurisdicional, além da complexidade que o sistema tem, tendo como uma possibilidade de melhora a implantação efetiva de um processo eletrônico no qual se procura tornar efetivo o direito fundamental de acesso à justiça.

Todavia, ainda há muito o que estudar sobre o assunto e ponderar pois nos dizeres de José Carlos de Araújo Almeida Filho:

\begin{abstract}
"Vivenciamos no Brasil um cenário de opostos. Ou muito se faz em termos de processo eletrônico, com decisões que podem, em um primeiro momento, demonstrar violação ao texto legal, ou nada se faz, inadimitindo-se recursos e outros atos processuais por meios eletrônicos. Ou, ainda, por incrível que pareça, com quase quatro anos de promulgação, Tribunais, como o do Rio de Janeiro, que se utilizam de simples remessa com
\end{abstract}

\footnotetext{
${ }_{14}$ THEODORO JÚNIOR, Humberto Theodoro, 2005, p.70 In Comentários a lei do processo eletrônico / coodernação José Eduardo de Resende Chaves Júnior. - São Paulo: LTr.2010, p. 81 In Um Contexto Multiforme de Acesso à Prestação Jurisdicional: Art.2 ${ }^{\circ}$, a Tramitação Processual Eletrônica de Wesley Roberto de Paula legislando, dada a possibilidade de competência concorrente para legislar entre a União e os Estados.
} 
base na Lei do Fax. Um atraso, um despreparo e uma contrariedade à celeridade.

É preciso, neste momento, com a vigência da Lei do Processo Eletrônico, que os meios eletrônicos sejam adotados para a pacificação de conflitos e provoquem uma celeridade no processo. Admitimos, por esta razão, estarmos tratando de procedimento e corremos o risco de termos Estados-membros

(...) podemos ousar e afirmar que um processo eletrônico não se apresenta uma idéia absurda e em breve teremos a necessidade de sua implantação para conflitos próprios da era eletrônica." 15

\section{O PROCESSO ELETRÔNICO SOB O PRISMA DOS DIREITOS HUMANOS}

Importante também afirmar que o processo eletrônico pode ser visto sob o prisma dos Direitos Humanos, já que muitos dos que precisam e necessitam de acesso à justiça, são muitas vezes, os que estão excluídos digitalmente da sociedade da informação na qual se insere o momento atual. $\mathrm{E}$ isso foi algo constatado pelo enviado Leandro Despouy da Organização das Nações Unidas, que em entrevista nacional afirmou que:

\section{CONCLUSÃO}

"Falta de Acesso à Justiça. Grande parte da população, por razões de ordem social, econômica ou exclusão não tem acesso à prestação jurisdicional. Essa situação se vê agravada quando se trata de grupos particularmente vulneráveis como: crianças, adolescentes, mulheres, indígenas, homossexuais, transexuais, quilombolas, negros, idosos, e os movimentos sociais, como os trabalhadores sem terra, os ambientalistas, entre outros.

Morosidade da Justiça. Entretanto, aqueles que chegam aos tribunais deparam-se com uma morosidade da justiça, o que dificulta e, em alguns casos, torna ineficaz a prestação jurisdicional." 16

Portanto, o processo eletrônico, mesmo que não seja capaz de eliminar todos os entraves ainda presentes em nosso ordenamento jurídico, ainda que alvo de elogios e críticas, é um meio pelo qual seria possível trazer à realidade jurídica brasileira, e à população dessa sociedade da informação, mais crença na resposta efetiva do direito que se pleiteia, sendo um início para a quebra da "rotulação" do Poder Judiciário da morosidade na prestação jurisdicional, fazendo assim, capaz de efetivar o direito fundamental de acesso à justiça.

Importante para que isso se efetive é fazer com que aqueles excluídos

15. ALMEIDA FILHO, José Carlos de Araújo,1967 - Processo eletrônico e teoria geral do processo eletrônico: a informatização judicial no Brasil/José Carlos de Araújo Almeida Filho. - Rio de Janeiro: Forense, 2010, p.21/22

16. Idem, p. 48 
digitalmente sejam de alguma forma inseridos através desse meio e concluindo sobre o assunto, o sobredito autor afirma: "Desafogar o Judiciário e proporcionar processos mais ágeis implica, necessariamente, condições de acesso à população mais carente - as que talvez mais necessitem do apoio do Estado para dirimir seus conflitos". (Almeida Filho, José Carlos de Araújo,1967 - Processo eletrônico e teoria geral do processo eletrônico: a informatização judicial no Brasil/José Carlos de Araújo Almeida Filho. - Rio de Janeiro: Forense, 2010, p.51)

Diante de todo o exposto, apesar de não ser o processo eletrônico a resposta de todos os problemas do nosso sistema jurídico, ele é um meio que pode possibilitar amenizar a burocracia existente no ordenamento jurídico brasileiro de modo a viabilizar a efetivação do direito fundamental de acesso à justiça e assim todos poderem vivenciar de modo mais "real" o preceito constitucional da duração razoável do processo, conseguindo, por conseguinte, a efetivação de seus direitos.

\section{BIBLIOGRAFIA}

ALMEIDA FILHO, José Carlos de Araújo, 1967 - Processo eletrônico e teoria geral do processo eletrônico: a informatização judicial no Brasil / José Carlos de Araújo Almeida Filho. - Rio de Janeiro: Forense, 2010;

BENUCCI, Renato Luís. A tecnologia aplicada ao processo judicial / Renato Luís Benucci.- Campinas, São Paulo: Millennium Editora, 2006;

CAPPELLETTI, Mauro. Acesso à justiça. Tradução de Ellen Gracie Northfleet. Porto Alegre, Fabris, 1988;

DINAMARCO, Cândido Rangel. Instituições de direito processual civil. São Paulo: Malheiros, 2001;

FORTES, Rafael Costa. Informatização do judiciário e o processo eletrônico. In http:/ /jus2.uol.com.br/doutrina/texto.asp?id=14101\&p=2, acessado em 20/10/2010;

GAJARDONI, Fernando da Fonseca. Técnicas de aceleração do processo / Fernando da Fonseca Gajardoni - São Paulo: Lemos \& Cruz, 2003;

THEODORO JÚNIOR, Humberto, 2005, p.70 In Comentários a lei do processo eletrônico / coodernação José Eduardo de Resende Chaves Júnior. - São Paulo: LTr.2010, p. 81 in Um Contexto Multiforme de Acesso à Prestação Jurisdicional: Art.2 $2^{\circ}$ a Tramitação Processual Eletrônica de Wesley Roberto de Paula;

SANTOS, Mário Ferreira dos. Dicionário de filosofia e ciências culturais. $1^{\circ}$ vol.ed. 2. Matese: São Paulo. 1964;

http://www.cnj.jus.br/images/hotsites/relatorio_cnj_formato_cartilhav2.pdf, acessado em 23/10/2010; 